\title{
Genetic Ancestry Is Associated With Systolic Blood Pressure and Glucose in Brazilian Children and Adolescents
}

\author{
Erica Maria de Queiroz ${ }^{\mathrm{a}, \mathrm{f}}$, Priscila Oliveira Barbosa ${ }^{\mathrm{a}}$, Ana Paula Candido ${ }^{\mathrm{b}}$, Ieso Miranda Castro ${ }^{\mathrm{c}}$, \\ George Luiz Lins Machado-Coelho ${ }^{\mathrm{d}}$, Tailce Moura Leite ${ }^{\mathrm{e}}$, Rinaldo Wellerson Pereira ${ }^{\mathrm{e}}$, \\ Renata Nascimento de Freitas ${ }^{\mathrm{a}}$
}

\begin{abstract}
Background: Studies in admixed populations show that the prevalence of obesity and related diseases, such as type 2 diabetes and hypertension, may vary by ethnic group. The aim of this study was to investigate the relationship of genetic ancestry with phenotypes associated with obesity in a sample of school children and adolescents from Ouro Preto, Minas Gerais.
\end{abstract}

Methods: We used data from genetic ancestry of 189 individuals previously determined by 15 ancestry informative markers (AIMs), and segregated individuals into three ancestral groups (predominantly African (PAFR), predominantly mixed (PMIX), and predominantly European (PEUR)) using the proportion of ancestry. The ancestral groups were compared with mean values of anthropometric, clinical, biochemical, and demographic variables. The simple linear regression analysis was used to test whether differences in mean values of the dependent variables (blood pressure and glucose) between the ancestral groups were dependent on the other variables.

Results: Our results show that the proportions of African $(\mathrm{F}=144.2$, $\mathrm{P}<0.001)$, Amerindian $(\mathrm{F}=15.5, \mathrm{P}<0.001)$ and European $(\mathrm{F}=$ $184.9, \mathrm{P}<0.001)$ ancestry differed significantly $(\mathrm{P}<0.001)$ among the three ancestral groups. PAFR individuals had higher mean blood pressure $(\mathrm{P} \leq 0.029)$ and glucose $(\mathrm{P}=0.025)$ as compared to PEUR. In the linear regression model, the difference in systolic blood pres-

Manuscript accepted for publication November 10, 2016

aDepartamento de Nutricao Clinica e Social, Nucleo de Pesquisas em Ciencias Biologicas, Universidade Federal de Ouro Preto, Ouro Preto, MG, Brazil

bepartamento de Nutricao, Universidade Federal de Juiz de Fora, Juiz de Fora, MG, Brazil

'Departamento de Farmacia, Nucleo de Pesquisas em Ciencias Biologicas, Universidade Federal de Ouro Preto, Ouro Preto, MG, Brazil

${ }^{\mathrm{d}}$ Departamento de Ciencias Medicas, Nucleo de Pesquisas em Ciencias Biologicas, Universidade Federal de Ouro Preto, Ouro Preto, MG, Brazil

ePrograma de Pos-Graduacao em Ciencias Genomicas e Biotecnologia, Universidade Catolica de Brasilia, Brasilia, DF, Brazil

${ }^{\mathrm{f} C o r r e s p o n d i n g ~ A u t h o r: ~ E r i c a ~ M a r i a ~ d e ~ Q u e i r o z, ~ U n i v e r s i d a d e ~ F e d e r a l ~ d e ~}$ Ouro Preto, Escola de Medicina, Campus Universitario, Morro do Cruzeiro, Ouro Preto, Minas Gerais, CEP35400-000, Brazil.

Email:mqerica@gmail.com

doi: https://doi.org/10.14740/jem383w sure (SBP) values remained significant in all models tested and independent of confounding variables $(\mathrm{P} \leq 0.041)$. The difference in diastolic blood pressure values observed in PAFR and PEUR groups did not remain significant when the metabolic profile was included in the tested model $(\mathrm{P}=0.097)$. The difference in glucose values was significant only between PMIX and PEUR groups and independent of the settings $(\mathrm{P} \leq 0.037)$.

Conclusion: The positive correlation between genetic ancestry and SBP and glucose in Brazilian children and adolescents suggests the need for special care in the subgroups of this population.

Keywords: Genetic ancestry; Obesity-related risk phenotypes; Brazilian population

\section{Introduction}

Admixed populations formed by mixing European (EUR), African (AFR), and Amerindians (AMR), such as the United States, Argentina, Puerto Rico, Mexico, and Brazil [1-5], have been studied to know the history of their ethnic background using ancestry-indicative markers (AIMs). AIMs are genetic markers that differ in allele frequencies between ancestral populations and have been used to infer the ethnic origin of populations [6]. In addition to being important in anthropological studies, knowing the ancestry of the population allows a better understanding of some diseases whose prevalence varies by ethnicity, for example, obesity, hypertension, and type 2 diabetes [7-12]. Studies in the US population, one of the most wellstudied admixed populations, show a positive correlation between African ancestry and higher values of body mass index (BMI), weight, leg length, lean mass, bone mineral density and lower values of fat mass, and total, intra- and subcutaneous abdominal fat $[9,13,14]$. Conversely, European ancestry has been inversely correlated with lean body mass, BMI, weight, hip circumference, and skinfold thickness subscapularis, and positively correlated with waist circumference adjusted for BMI [14-16].

The population of Ouro Preto, State of Minas Gerais, southeastern Brazil, presents significant African influence as well as other admixed populations $[1,4]$. Data from the census conducted by the Brazilian Institute of Geography and Sta- 
Table 1. Anthropometric, Biochemical, Clinical, and Demographic Characteristics of the Ancestral Groups, Predominantly African (PAFR), Predominantly European (PEUR) and Predominantly Mixed (PMIX)

\begin{tabular}{|c|c|c|c|c|}
\hline Variable & $\operatorname{PAFR}(n=16)$, mean $(\mathrm{SD})$ & PMIX $(n=122)$, mean (SD) & PEUR $(n=51)$, mean $(S D)$ & $\mathbf{P}$ \\
\hline Proportion of African markers & $0.705(0.1)$ & $0.374(0.2)$ & $0.119(0.1)$ & $<0.001$ \\
\hline Proportion of Amerindian markers & $0.113(0.1)$ & $0.202(0.2)$ & $0.090(0.1)$ & $<0.001$ \\
\hline Age (years) & $11.6(2.0)$ & $10.6(1.9)$ & $10.2(2.2)$ & 0.043 \\
\hline Weight (kg) & $46.5(15.6)$ & $41.8(14.7)$ & $39.9(15.5)$ & 0.306 \\
\hline Percentage of body fat $(\%)$ & $32.3(3.8)$ & $31.1(7.8)$ & $29.5(8.2)$ & 0.338 \\
\hline Waist circumference $(\mathrm{cm})$ & $70.9(12.0)$ & $66.5(11.3)$ & $65.0(13.0)$ & 0.228 \\
\hline Birth weight $(\mathrm{kg})$ & $3.0(817.3)$ & $3.0(662.1)$ & $3.1(564.2)$ & 0.843 \\
\hline Diastolic blood pressure (mm Hg) & $67.4(10.1)$ & $63.2(9.3)$ & $60.4(9.3)$ & 0.029 \\
\hline LDL-C (mg/dL) & $98.4(27.6)$ & $94.1(25.8)$ & $95.3(32.6)$ & 0.832 \\
\hline Triglycerides (mg/dL) & $63.6(36.9)$ & $82.0(37.5)$ & $89.6(68.8)$ & 0.167 \\
\hline Glucose (mg/dL) & $84.0(8.9)$ & $85.9(8.1)$ & $82.2(7.7)$ & 0.025 \\
\hline Insulin $(\mu \mathrm{U} / \mathrm{mL})$ & $8.2(4.8)$ & $8.8(8.3)$ & $6.9(3.8)$ & 0.415 \\
\hline HOMA-IR & $1.8(1.2)$ & $1.9(2.0)$ & $1.4(0.8)$ & 0.329 \\
\hline
\end{tabular}

Data are reported as means \pm SD. P value for ANOVA for continuous variables tested for comparison of frequency between ancestral groups. LDLC: low-density lipoprotein-cholesterol; HDL-C: high-density lipoprotein-cholesterol; HOMA-IR: homeostasis model assessment of insulin resistance.

tistics (IBGE) conducted in 2010 show that the city's population is composed of $14.4 \%$ black, according to the classification of self-reported skin color [17]. Previous studies of genetic ancestry revealed that the African genetic contribution is even greater in this population, accounting for 33.3\% [18]. Additionally, the population is marked by a high prevalence of excess weight and obesity in adults $(30 \%$ overweight and $11.9 \%$ obese), in children and adolescents $(8.7 \%$ overweight and $6.2 \%$ obese) $[19,20]$, and high morbidity $(27.5 \%)$ due to diseases related to the circulatory system [17]. Among children and adolescents of this city, a prevalence has been observed for hypertension (5\%), high prevalence of physical inactivity $(73.9 \%)$, and high concentrations of total cholesterol $(36.9 \%)$ and low-density lipoprotein-cholesterol (LDL-C) (5.8\%), and low concentrations of high-density lipoprotein-cholesterol (HDL-C) $(18.6 \%)$. In addition, $44.4 \%$ of children participants had 2 - 3 risk factors and $8.2 \%$ had 4 - 6 risk factors for cardiovascular diseases [20]. These data indicate that the population of Ouro Preto requires care. Although it is known that the prevalence of obesity and diseases related to cardiovascular morbidity, e.g., type 2 diabetes, hypertension, and dyslipidemia [8], may differ between ethnic groups, no epidemiological study has been carried out using genetic ancestry to segregate ethnic groups in the population.

In this study, we segregate a sample of Ouro Preto's population into groups according to the predominance of AIMs and evaluate the distribution of risk factors for cardiovascular dis- eases.

\section{Materials and Methods}

\section{Study design}

The study sample was composed of 189 individuals (10.6 \pm 2.04 years) randomly selected from the cross-sectional study performed in 2006 in Ouro Preto, in southeastern Brazil [20]. The volunteers' legal guardians signed a consent form. This project was approved by the Research Ethics Committee of the Federal University of Ouro Preto.

The levels of lipids and glucose were performed by enzymatic colorimetric assay using a commercial kit (In Vitro Diagnostics, Itabira, MG, Brazil) and the Airone 200 (Crony Instruments, Rome, Italy). Insulin was determined by test access ultrasensitive insulin (Access Immunoassay System ${ }^{\circledR}$ ) and homeostasis model assessment of insulin resistance (HOMA-IR) was calculated using the formula: (fasting plasma glucose $(\mathrm{mmol} / \mathrm{L}) \times$ fasting plasma insulin $(\mathrm{mU} / \mathrm{L})) / 22.5$. Weight was measured using a Tanita BF542 ${ }^{\circledR}$ (Tanita Corporation of America, Arlington Heights, IL, USA), and height and waist circumference (WC) were measured using a stadiometer (WCS Cardiomed, Curitiba, Brazil). BMI was calculated by dividing the weight $(\mathrm{kg})$ and height squared $\left(\mathrm{m}^{2}\right)$. The tetrapolar bioelectrical impedance method was used to 
Table 2. Simple Linear Regression Analysis for Distribution of Blood Pressure and Glucose Among Different Ancestral Groups Adjusted for Covariates

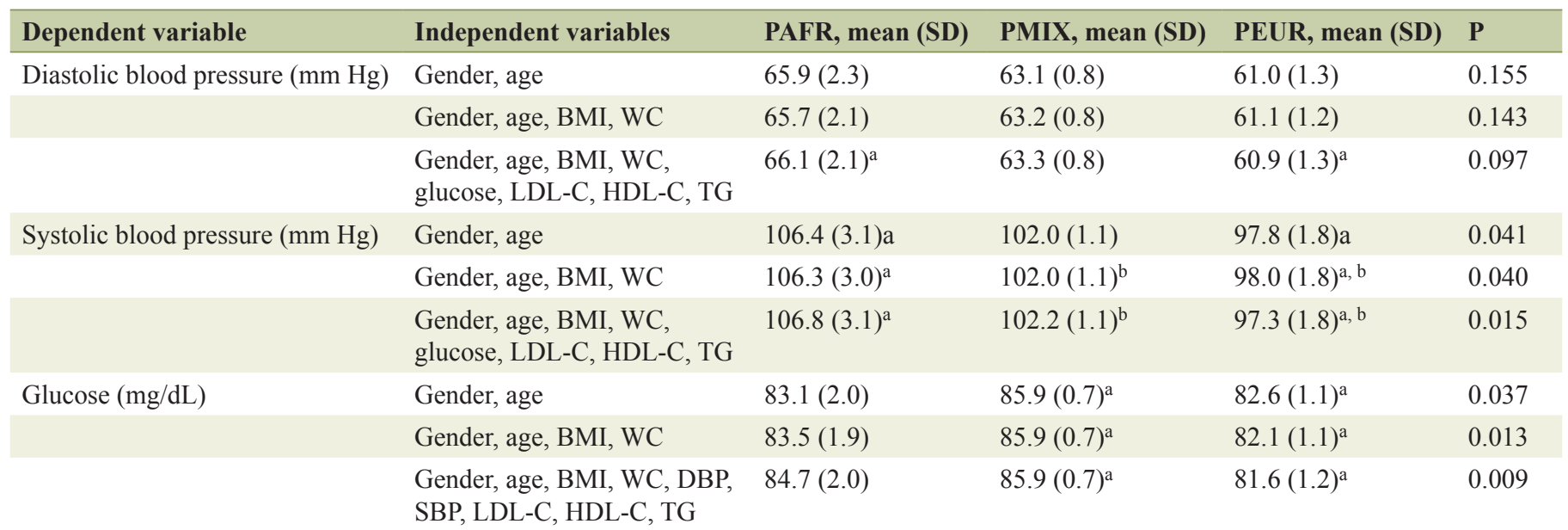

Data are reported as mean \pm SD. PAFR: predominantly African; PEUR: predominantly European; PMIX: predominantly mixed; BMI: body mass index; WC: waist circumference; DBP: diastolic blood pressure; SBP: systolic blood pressure; LDL-C: low-density lipoprotein-cholesterol; HDL-C: high-density lipoprotein- cholesterol; TG: triglycerides. ${ }^{*} \mathrm{P}$ value for simple linear regression analysis for distribution of blood pressure and glucose among different ancestral groups adjusted for covariates. a, bSignificant differences between pairs of ancestral groups (PAFR, PMIX, and PEUR).

assess body fat percent by Deurenberg et al (1990) [21]. Blood pressure was measured three times at intervals of 10 min using pressure monitor Onrom ${ }^{\circledR}$ 705CP (Onrom Healthcare, Kyoto, Japan) with the volunteer being seated and his/her left arm held at heart level, and repeated by auscultation when the average exceeded the 90th percentile. The mean of three blood pressure measurements was considered.

Using the data of predetermined genetic ancestry for this same population sample [18], we subdivided the sample of individuals into two groups: 1) predominantly African (PAFR) and 2) predominantly European (PEUR), according to the predominance in proportion of AIMs ( $\geq 65 \%$ ) of each African or European parental population, respectively. The third group (predominantly mixed (PMIX)) was composed by a single individual who presented $\geq 65 \%$ of Amerindian AIMs and by all individuals who showed no predominance of any of the markers $(<65 \%$ of the all ancestral AIMs).

To test for differences between ancestries groups, we used one-way analysis of variance (ANOVA) for continuous variables. The simple linear regression analysis was used to test whether differences in mean values of the dependents variables (blood pressure and glucose) between the ancestral groups (PAFR, PEUR and PMIX) were independent of the other variables: gender, age, BMI, WC, glucose, LDL-C, HDL-C, triglycerides (TG), systolic blood pressure (SBP), and diastolic blood pressure (DBP). Statistical analyses were performed using SPSS 18.0 (Chicago, IL, USA). P values equal to or less than 0.05 were considered statistically significant.

\section{Results}

This study involved a sample of 189 subjects, 101 (53.4\%) girls and $88(46.6 \%)$ boys, with a mean age of $10.6 \pm 2.04$ years.

Table 1 summarizes the distribution of the mean values of anthropometric, biochemical, clinical, and demographic characteristics evaluated for the individuals of the PAFR, PEUR, and PMIX groups. The PAFR group had on average $70.5 \%$ of African ancestry markers. The PEUR group had on average $79.1 \%$ of European ancestry markers. The PMIX group had on average $42.4 \%, 37.4 \%$, and $20.2 \%$ of the European, African, and Amerindian markers, respectively. The ANOVA by a factor revealed that the average proportions of African $(\mathrm{F}=144.2$, $\mathrm{P}<0.001)$, Amerindian $(\mathrm{F}=15.5, \mathrm{P}<0.001)$, and European $(\mathrm{F}$ $=184.9, \mathrm{P}<0.001)$ ancestry differed significantly $(\mathrm{P}<0.001)$ among the three ancestral groups. According to the distribution of average values of the variables, the PAFR group showed higher values by age $(\mathrm{P}=0.043)$, DBP $(\mathrm{P}=0.029)$, SBP $(\mathrm{P}$ $=0.011)$, and glucose $(\mathrm{P}=0.025)$ as compared to the PEUR group. The PMIX group had higher glucose and intermediate values of blood pressure values as compared to the other two groups (PAFR and PEUR). There was no significant difference between the ancestral groups regarding the average values of other tested continuous variables (Table 1).

Table 2 shows analysis results using the simple linear regression model. According to the DBP values, although the PAFR group had DBP values higher than the other groups, this difference was significant only among the PAFR and PEUR groups for the third model tested. Moreover, this difference did not remain significant after adjustment for glucose, LDL-C, HDL-C, and TG $(P=0.097)$. The PAFR group had significantly higher SBP than did the PEUR, as well as the PMIX and PEUR groups in almost all models. This observed difference in SBP values between the ancestral groups was independent of sex, age, BMI, $\mathrm{WC}$, glucose, LDL-C, HDL-C, and TG $(\mathrm{P} \leq 0.041)$. The PAFR group showed higher but not significant glucose values than that observed for PEUR. Significant differences in glucose values were observed between the PMIX and PEUR groups in all models. These differences were independent of gender, age, BMI, WC, SBP, DBP, LDL-C, HDL-C, and TG (P $\leq 0.037)$. 


\section{Discussion}

In this study, we investigated whether there is relationship between genetic ancestry and obesity-related risk phenotypes in a sample of children and adolescents $(n=189)$ from Ouro Preto, Minas Gerais, Brazil. To conduct this study, we used the highest cutoff point value of the AIMs (65\%), which provided a reasonable number of individuals per ancestries groups. We believe that this cutoff value is appropriate because it is greater than the average value of the European AIMs described for Ouro Preto's population (50.3-53.9\%) [18], and is the average of which is observed to southeastern Brazilian population (55.2-79.9\%) [5, 22-24].

Although the prevalence of obesity, type 2 diabetes, and hypertension differs between ethnic groups, there are few correlation studies between genetic ancestry and risk phenotypes for these diseases. The association of higher SBP values with a higher proportion of African AIMs observed in our study corroborates with the results obtained for other admixed populations [25-28]. However, different results have also been observed [1,29]. According Rizos and Elisaf (2014) [30], hypertension is an important risk factor in the development and progression of cardiovascular disease. Furthermore, hypertension manifests differently according to the patient's ancestral origin. Patients with African ancestry, for example, have a higher prevalence, higher severity, and early onset of hypertension, and a distinct response to treatment by antihypertensive medication as compared to the general population. Thus, it is important to consider all factors that could affect the choice, conduct, and response to treatment of arterial hypertension.

The association of higher glucose values with a higher proportion of African AIMs as compared to Europeans AIMs observed in our study corroborates with the results obtained by Reiner et al (2005) [1]. Additionally, the positive association between a higher proportion of African markers and insulin resistance has been reported in the US population [29], and different results have been described for the association between African markers and type 2 diabetes [25, 31].

The small number of subjects per ancestral group and the small number of the AIMs used were limitations to this study. However, this is an original study of an understudied population, and our results reinforce the idea that the prevalence of hypertension and diabetes may vary according to the proportion of AIMs in a population. Therefore, the search for risk factors, clinical manifestations, and treatment for these diseases should consider their genetic differences.

In conclusion, our results revealed associations between genetic ancestry and SBP and glucose values in Brazilian children and adolescents, which could suggest increased risk for cardiovascular diseases or type 2 diabetes for individuals with a prevalence of African AIMs.

\section{Acknowledgments}

We thank Julio Cesar Rodrigues Fontenelle for suggestions and statistical analysis.

\section{Conflicts of Interest}

The authors declare no conflicts of interest.

\section{Grant Support}

Research was supported by Conselho Nacional de Desenvolvimento Cientifico e Tecnologico (CNPq, \#47.4965/2004-0), Coordenacao de Aperfeicoamento de Pessoal de Nivel Superior (CAPES), Fundacao de Amparo a Pesquisa do Estado de Minas Gerais (FAPEMIG, EDT-\#325/05, EDT-CDS \#770/05, CDS-APQ-\#00519-09, CBB-APQ-\#02260-10), Fundacao de Apoio a Pesquisa do Distrito Federal (FAP-DF), and Pro-Reitoria de Pos-Graduacao e Pesquisa from Universidade Federal de Ouro Preto and from Universidade Catolica de Brasilia (PRPGP-UCB), Brazil.

\section{References}

1. Reiner AP, Ziv E, Lind DL, Nievergelt CM, Schork NJ, Cummings SR, Phong A, et al. Population structure, admixture, and aging-related phenotypes in African American adults: the Cardiovascular Health Study. Am J Hum Genet. 2005;76(3):463-477.

2. Seldin MF, Tian C, Shigeta R, Scherbarth HR, Silva G, Belmont JW, Kittles R, et al. Argentine population genetic structure: large variance in Amerindian contribution. Am J Phys Anthropol. 2007;132(3):455-462.

3. Martinez-Fierro ML, Beuten J, Leach RJ, Parra EJ, CruzLopez M, Rangel-Villalobos H, Riego-Ruiz LR, et al. Ancestry informative markers and admixture proportions in northeastern Mexico. J Hum Genet. 2009;54(9):504-509.

4. Via M, Gignoux CR, Roth LA, Fejerman L, Galanter J, Choudhry S, Toro-Labrador G, et al. History shaped the geographic distribution of genomic admixture on the island of Puerto Rico. PLoS One. 2011;6(1):e16513.

5. Pena SD, Di Pietro G, Fuchshuber-Moraes M, Genro JP, Hutz MH, Kehdy Fde S, Kohlrausch F, et al. The genomic ancestry of individuals from different geographical regions of Brazil is more uniform than expected. PLoS One. 2011;6(2):e17063.

6. Shriver MD, Smith MW, Jin L, Marcini A, Akey JM, Deka R, Ferrell RE. Ethnic-affiliation estimation by use of population-specific DNA markers. Am J Hum Genet. 1997;60(4):957-964.

7. Brito IC, Lopes AA, Araujo LMB. Associacao da Cor da Pele com Diabetes Mellitus Tipo 2 e Intolerancia a Glicose em Mulheres Obesas de Salvador, Bahia. Arq Bras Endocrinol Metab. 2001;45(5):475-480.

8. Cossrow N, Falkner B. Race/ethnic issues in obesity and obesity-related comorbidities. J Clin Endocrinol Metab. 2004;89(6):2590-2594.

9. Shaffer JR, Kammerer CM, Reich D, McDonald G, Patterson N, Goodpaster B, Bauer DC, et al. Genetic markers for ancestry are correlated with body composition traits in older African Americans. Osteoporos Int. 
2007;18(6):733-741.

10. Vieira MP, Carmona DPD, Anjos LA, Souza T, Espinosa MM, Ribeiro RLR, Barbosa DA. High blood pressure in children and teenagers from public schools in Cuiaba, Mato Grosso. Acta Paul Enferm. 2009;22:473-475.

11. Sekhobo JP, Edmunds LS, Reynolds DK, Dalenius K, Sharma A. Trends in prevalence of obesity and overweight among children enrolled in the New York State WIC program, 2002-2007. Public Health Rep. 2010;125(2):218224.

12. Cowie CC, Rust KF, Byrd-Holt DD, Gregg EW, Ford ES, Geiss LS, Bainbridge KE, et al. Prevalence of diabetes and high risk for diabetes using A1C criteria in the U.S. population in 1988-2006. Diabetes Care. 2010;33(3):562568.

13. Fernandez JR, Shriver MD, Beasley TM, Rafla-Demetrious N, Parra E, Albu J, Nicklas B, et al. Association of African genetic admixture with resting metabolic rate and obesity among women. Obes Res. 2003;11(7):904-911.

14. Cardel M, Higgins PB, Willig AL, Keita AD, Casazza K, Gower BA, Fernandez JR. African genetic admixture is associated with body composition and fat distribution in a cross-sectional study of children. Int J Obes (Lond). 2011;35(1):60-65.

15. Cheng CY, Kao WH, Patterson N, Tandon A, Haiman CA, Harris TB, Xing C, et al. Admixture mapping of 15,280 African Americans identifies obesity susceptibility loci on chromosomes 5 and X. PLoS Genet. 2009;5(5):e1000490.

16. Cheng CY, Reich D, Coresh J, Boerwinkle E, Patterson $\mathrm{N}$, Li M, North KE, et al. Admixture mapping of obesity-related traits in African Americans: the Atherosclerosis Risk in Communities (ARIC) Study. Obesity (Silver Spring). 2010;18(3):563-572.

17. IBGE Instituto Brasileiro de Geografia e Estatistica. Sintese de indicadores sociais: IBGE. 2010; available at [http://www.ibge.gov.br]. Acessed 04 October 2011.

18. Queiroz EM, Santos AM, Castro IM, Machado-Coelho GL, Candido AP, Leite TM, Pereira RW, et al. Genetic composition of a Brazilian population: the footprint of the Gold Cycle. Genet Mol Res. 2013;12(4):5124-5133.

19. de Freitas SN, Caiaffa WT, Cesar CC, Faria VA, do Nascimento RM, Coelho GL. Nutritional risk in the urban population of Ouro Preto, southeastern region of Brazil: the Ouro Preto heart study. Arq Bras Cardiol. 2007;88(2):191-199.

20. Candido AP, Benedetto R, Castro AP, Carmo JS, Nicolato RL, Nascimento-Neto RM, Freitas RN, et al. Cardiovascular risk factors in children and adolescents living in an urban area of Southeast of Brazil: Ouro Preto Study. Eur
J Pediatr. 2009;168(11):1373-1382.

21. Deurenberg P, Pieters JJ, Hautvast JG. The assessment of the body fat percentage by skinfold thickness measurements in childhood and young adolescence. Br J Nutr. 1990;63(2):293-303.

22. Lins TC, Vieira RG, Abreu BS, Grattapaglia D, Pereira RW. Genetic composition of Brazilian population samples based on a set of twenty-eight ancestry informative SNPs. Am J Hum Biol. 2010;22(2):187-192.

23. Giolo SR, Soler JM, Greenway SC, Almeida MA, de Andrade M, Seidman JG, Seidman CE, et al. Brazilian urban population genetic structure reveals a high degree of admixture. Eur J Hum Genet. 2012;20(1):111-116.

24. Manta FS, Pereira R, Caiafa A, Silva DA, Gusmao L, Carvalho EF. Analysis of genetic ancestry in the admixed Brazilian population from Rio de Janeiro using 46 autosomal ancestry-informative indel markers. Ann Hum Biol. 2013;40(1):94-98.

25. Lai CQ, Tucker KL, Choudhry S, Parnell LD, Mattei J, Garcia-Bailo B, Beckman K, et al. Population admixture associated with disease prevalence in the Boston Puerto Rican health study. Hum Genet. 2009;125(2):199-209.

26. Cheng CY, Reich D, Wong TY, Klein R, Klein BE, Patterson N, Tandon A, et al. Admixture mapping scans identify a locus affecting retinal vascular caliber in hypertensive African Americans: the Atherosclerosis Risk in Communities (ARIC) study. PLoS Genet. 2010;6(4):e1000908.

27. Kosoy R, Qi L, Nassir R, Garcia L, Allison M, Shigeta R, Robbins J, et al. Relationship between hypertension and admixture in post-menopausal African American and Hispanic American women. J Hum Hypertens. 2012;26(6):365-373.

28. Shahabi A, Wilson ML, Lewinger JP, Goodwin TM, Stern $\mathrm{MC}$, Ingles SA. Genetic admixture and risk of hypertensive disorders of pregnancy among Latinas in Los Angeles County. Epidemiology. 2013;24(2):285-294.

29. Reiner AP, Carlson CS, Ziv E, Iribarren C, Jaquish CE, Nickerson DA. Genetic ancestry, population sub-structure, and cardiovascular disease-related traits among African-American participants in the CARDIA Study. Hum Genet. 2007;121(5):565-575.

30. Rizos CV, Elisaf MS. Antihypertensive drug therapy in patients with African ancestry. Expert Opin Pharmacother. 2014;15(8):1061-1064.

31. Cheng CY, Reich D, Haiman CA, Tandon A, Patterson N, Selvin E, Akylbekova EL, et al. African ancestry and its correlation to type 2 diabetes in African Americans: a genetic admixture analysis in three U.S. population cohorts. PLoS One. 2012;7(3):e32840. 